\title{
Zola, el naturalismo y la identidad nacional en tres dramas de Florencio Sánchez
}

\section{Francisco García Rubio}

Los elementos naturalistas en la dramaturgia de Florencio Sánchez ofrecen un tema tan amplio y complejo que, incluso con un enfoque restringido en unas pocas obras, propone conclusiones significativas. En el presente trabajo se demostrará cómo en piezas teatrales como La gringa (1904), La pobre gente (1904) y Barranca abajo (1905) los elementos naturalistas, principalmente el de la degeneración atávica, brindan no sólo un teatro con inquietud social sino que plantean un cuadro de problemáticas en torno a las estructuras socioeconómicas y a la identidad nacional que se originan en el seno de la sociedad argentina de principios de siglo.

La primera parte del presente trabajo se concentra en los postulados que Emile Zola propone para un teatro naturalista y el alcance que tienen éstos en los dramas de Florencio Sánchez. De este modo se analizará la incidencia de los elementos naturalistas que unen estas tres obras: la degeneración atávica, la herencia y el factor ambiental. En la segunda parte, analizaré el uso ideológico que le da Florencio Sánchez para tratar de desentrañar las complejas problemáticas endémicas de una sociedad en plena transición en sus estructuras económicas e identitarias. Con ello, Florencio Sánchez va a someter su dramaturgia a una función social tal como postula Emile Zola. De este modo el teatro servirá como un instrumento capaz no ya sólo de mostrar la realidad, sino también intentar transformar una sociedad que hereda las problemáticas sociales de la Europa finisecular, pero que también se interfiere con las complejidades ideológicas de la identidad nacional argentina.

Laureano Bonet, recopilador de una serie de ensayos de Emile Zola, bajo el nombre de El naturalismo (1989), ubica el nacimiento del movimiento naturalista con la publicación de La novela experimental (1879). Zola irrumpe así en el panorama intelectual europeo de finales de siglo XIX con la incor- 
poración del método científico-experimental del fisiólogo Claude Bernard. Según Bonet, el naturalismo de Zola es un método intelectual con vocación totalizadora que pretende ir más allá de una fórmula o estilo literario concreto (16) y "se trata de un método de pensamiento y visión de la vida que todo escritor puede, luego, encajar con su personalísimo sistema retórico" (24). Zola postula que la aplicación de la metodología experimental, ya sea a las letras o a las ciencias, conducirá inevitablemente a una explicación lógica y racional de los fenómenos naturales, individuales y sociales, que la metafísica tendía a atribuir a causas sobrenaturales.

Igualmente Zola pretende dar cuenta de la observación desinteresada mediante el uso del método científico y tratar de buscar las condiciones necesarias que se dan en la naturaleza, incluida la humana, para hallar la causa de los fenómenos sociales y qué factores los determinan. Precisamente ese determinismo social será el que, según Zola, sirva para "dejar a los legisladores, a los hombres de práctica, el cuidado de adquirir, tarde o temprano, estos fenómenos de manera que se desarrollen los buenos y se reduzcan los malos, desde el punto de vista de la utilidad humana" (53). Esta observación o experimentación de las problemáticas sociales conducirá inevitablemente al escritor naturalista a representar el mundo de los vicios, de lo morboso y lo degenerado, regido por determinantes hereditarios y ambientales.

Para Zola la función social del teatro no pasó desapercibida en sus postulados naturalistas, pese a que siempre se asocie este movimiento a la novela. El autor francés contempla en su ensayo El Naturalismo en el teatro (1881) la posibilidad de una dramaturgia de carácter naturalista, cuando afirma que "nuestro teatro será naturalista o no será" (146), en clara referencia a la supervivencia del género dramático frente a la novela, la cual empezaba a gozar de una preferencia hegemónica del gran público. Por esta razón los postulados de Zola acerca de lo que debería ser el nuevo teatro, si bien se supedita a las características propias de la novela naturalista, invitan a explorar las potencialidades del teatro: "No hay que olvidar el maravilloso poder del teatro, su efecto inmediato sobre el espectador. No existe instrumento mejor de propaganda" (140). Esta decadencia del teatro frente a la novela se debía, según Zola, a que esta última poseía una versatilidad que se acomodaba más al gusto de un gran público que demandaba cada vez más narrativas cercanas a una realidad verídica.

Zola parte de la idea de que el dramaturgo nada tiene que hacer frente al novelista, y por esta razón se ha de dirigir a esa masa social, "que tiene necesidad de claridad y concisión" (140). El dramaturgo de este modo ha de 
plasmar con transparencia y concisión una escena que sea "una evocación material de la vida" (140). Sería, en definitiva traducir necesariamente el elemento descriptivo naturalista de la novela en un decorado escénico preciso en el teatro, que pueda expresarse por sí solo. Igualmente Zola postula que el lenguaje escénico debe ser natural, pero sobre todo tener en consideración que "el mejor estilo en el teatro es el que resume mejor la conversación hablada, el que pone la palabra justa en su lugar con el valor que debe tener" (144). Respecto a los personajes, éstos habrán de ser tomados de esa realidad negra y austera, pese a que no goce de la preferencia del público que llena habitualmente los teatros, porque el fin último de este género es que acerque la verdad a los espectadores. En definitiva, puede decirse que la concepción de Zola sobre la dramaturgia se resumiría en el "estudio y la descripción de la vida" (145), dotando al género de una función social y utilitaria.

Todas estas formulaciones teóricas expuestas por Zola en torno a la posibilidad de una estética naturalista en el teatro, parecen estar especialmente recogidas en una serie de tres dramas de Florencio Sánchez, que produce en apenas dos años La gringa (1904), La pobre gente (1904) y Barranca abajo (1905). La claridad y la concisión que se observan en estos tres dramas son referentes inmediatos de las problemáticas que se plantean en una sociedad en plena ebullición de transformaciones sociales y económicas. ${ }^{1}$ Precisamente la representación del gaucho en La gringa y en Barranca abajo parece metaforizarse como un rasgo de degeneración atávica de una sociedad que sufre las traumáticas consecuencias de una transición en el modo de producción rural al industrial sobre todo de la ganadería extensiva. Pero igualmente puede advertirse que esa representación anacrónica del gaucho libre en la pampa argentina viene a exponer de manera clara y concisa que las viejas estructuras jurídicas de un derecho consuetudinario van a ser cercadas por un sistema jurídico de corte positivista.

Estos cambios jurídicos y económicos de marcado signo capitalista pueden observarse de igual modo en el ámbito urbano en el drama La pobre gente. El obrero sufrirá las consecuencias de no poder ubicarse en esa vorágine industrial de cambios en las estructuras productivas. El abaratamiento de la mano de obra provocará un incremento de la pobreza que repercutirá directamente sobre el modelo familiar tradicional argentino de finales de siglo. De este modo el obrero de la gran ciudad sufrirá las problemáticas sociales derivadas de la falta de trabajo, el alcoholismo, la marginación y la consecuente degradación moral. Pero además de las dificultades económicas provocadas por los desajustes de la oferta y la demanda del capitalismo 
industrial, la llegada de una inmigración cualificada provocará el aumento de las fricciones de carácter xenófobo. ${ }^{2}$

Estas situaciones sociales que se recrean en las tres piezas de Sánchez parecen incidir en los postulados de Zola sobre el teatro naturalista, a través de una evocación material de la vida cotidiana, que se refuerzan con un decorado escénico preciso y sobre todo una acomodación del lenguaje a cada uno de los personajes que intervienen. Su especial interés en ciertos detalles de las acotaciones sobre los decorados, pese a su fama de autor descuidado, va encaminado a ofrecer el fiel reflejo de esa negra y austera realidad que envuelve y determina la conducta de los personajes en la escena. Así se constata en el primer acto de Barranca abajo, cuando se describe inicialmente el hogar de Don Zoilo y su familia como "una casa antigua, pero de buen aspecto" (146), para posteriormente convertirse en un rancho austero y abandonado, reflejándose de este modo una degeneración económica y social. Igualmente puede observarse la misma circunstancia en las acotaciones sobre el decorado de La pobre gente, donde todo el dramático ambiente de pobreza, marginación económica y social de la gran ciudad se escenifica en algo parecido a la "habitación pobre de un conventillo" (201). Sánchez trata con ello de captar el espíritu naturalista de Zola escenificando con la mayor crudeza posible las condiciones míseras de la clase obrera bonaerense, que curiosamente no se hallaban muy lejos de los teatros donde representaban sus obras.

Otro aspecto del naturalismo de Zola presente en la obra de Sánchez es la espontaneidad en el flujo discursivo de sus personajes. Avenir Rossel afirmaba que la naturalidad en el lenguaje de Sánchez se proyecta en toda la escenificación a través de lo que denomina "situación de discurso" (91). Rossel denomina esta "situación de discurso" como la totalidad o "conjunto de circunstancias en medio de las cuales se desarrolla un acto de enunciación oral o escrito. Tales circunstancias comprenden el entorno físico y social en que se realiza ese acto, la imagen que tienen de él los interlocutores, la identidad de estos últimos" (91). Así puede explicarse el lenguaje arcaizante de Don Zoilo en Barranca abajo, y que contrasta radicalmente con los rasgos lingüísticos extranjerizantes que caracterizan al italiano Nicola de La gringa o los modismos arrabaleros rioplatenses que aparecen en La pobre gente.

Con esta multiplicidad de registros, Sánchez busca que el espectador se asome a la realidad de una serie de clases sociales menos favorecidas y desplazadas del desarrollo industrial de principios de siglo tanto en el ámbito rural como urbano de la sociedad argentina. La evocación dramatizada de estos diversos modos de hablar busca mostrar al espectador no sólo la 
extracción social o cultural de cada personaje, sino el factor ambiental que condiciona o determina la causa y el efecto de las problemáticas sociales que escenifican. Desde esta perspectiva podría decirse que los postulados de la corriente naturalista de Zola en estas tres obras parecen buscar un teatro de concienciación social para promover cambios de unas problemáticas sociales

Sin embargo, pese a que Dardo Cuneo en la década de los sesenta advirtiese tímidamente el influjo del naturalismo en la obra de Sánchez (1015), Julio Durán-Cerda señala que "el naturalismo en vigencia por entonces se da en Barranca abajo en su modalidad americana, es decir una modalidad atenuada por su liberación de la rigidez científica impuesta por el experimentalismo teórico de Emile Zola" (48). El análisis de Durán-Cerda de Barranca abajo se fundamenta única y exclusivamente en los criterios cientificistas de Hippolyte Taine. Sin embargo, parece prescindir de los postulados teóricos de Zola que expone en su El naturalismo en el teatro. No obstante, coincido con Durán-Cerda cuando afirma la existencia de un naturalismo en "modalidad americana," pero no por esa presunta "liberación de la rigidez científica" de Zola, sino por las nuevas problemáticas que aporta Sánchez a la literatura naturalista, como es el tema de la identidad nacional, las dialécticas étnicoraciales o la lucha contra la naturaleza, todas ellas temáticas que alejan al naturalismo americano del europeo por sus diferentes peculiaridades históricas y sociales.

Por otro lado, el rasgo esencial más caracterizado de estas tres piezas de Sánchez es el determinismo, esto es, el conjunto de condicionantes que tienen los personajes y que los conducen necesariamente a un proceso degradativo en el contexto social. El factor de índole genética en confluencia con el hábitat y el ambiente social, recrea a unos personajes que parecen estar abocados de manera irremediable a un destino, cuya causa parece encontrarse inherente en ellos mismos. En el ensayo "La novela experimental," Zola era contundente en este aspecto cuando afirmaba su creencia en estos factores: "Creo que la cuestión de la herencia tiene mucha influencia en las manifestaciones intelectuales y pasionales del hombre. También doy una importancia considerable al medio ambiente. Tendríamos que abordar las teorías de Darwin" (44).

Desde esta perspectiva, Sánchez parece seguir a Zola cuando esboza una somatización de sus personajes que se relaciona muy estrechamente con todos estos condicionantes. Se centra principalmente en la figura del gaucho en el ámbito rural y el obrero en el urbano. Estos personajes tienen un carácter acentuadamente arraigado en la visión tradicional de la identidad 
argentina pre-sarmientista. Sin embargo, Sánchez logra metaforizar a estos personajes como representantes de una colectividad que no va a tener cabida en la futura nación, puesto que van encaminados hacia su propia extinción, como el suicidio de Don Zoilo en Barranca abajo o la amputación del brazo de Don Cantalicio en La Gringa, mediante una trama donde los personajes entran en una fase de degeneración de sus rasgos atávicos.

Precisamente el naturalismo francés incorporará a su corpus ideológico el tema de la degeneración atávica, aunque su origen tuviera lugar poco antes de mediados del siglo XIX con la publicación de la obra de Benedict Morel Traité de dégénérescences physiques, intellectuelles et morales de l'espèce humaine. Morel estudiaba hasta qué punto la degeneración somática estaba en estrecha relación con las leyes de la herencia, postulando que dicho proceso degenerativo del cuerpo humano se basaba en una serie de transformaciones de los caracteres hereditarios que derivaban hacia la enfermedad y que su progresión era creciente en la cadena genealógica.

El naturalismo americano, sobre todo el argentino, acogerá todas estas ideas a principio de siglo. Gabriela Nouzeilles señala que esta obsesión por la "medicalización" (24) fue una constante en el naturalismo argentino de finales del siglo XIX y principios del XX, llegándose a imponer una serie de pautas en la sociedad de aquellos tiempos, donde:

la norma establecía el perfil de un tipo deseable que tendía a confundirse con el retrato de un joven burgués, heterosexual y blanco, al mismo tiempo que los rasgos degenerativos, de índole física o moral, coincidían en general con los criterios de caracterización de ciertos grupos sociales cuya inferioridad nacía de su misma colocación con respecto del modelo en términos de su edad (niños, ancianos), su sexo (mujeres, homosexuales), su clase (aristócratas, campesinos, obreros), su status legal (criminales, menores) y/o su raza (negros, indios, asiáticos). (45)

En la obra de Sánchez la figura del gaucho (Don Zoilo y Don Cantalicio), e incluso alguno de sus descendientes (Robustiana en Barranca abajo) es presentada en la vejez, enfermas o imposibilitadas para hacer frente a la nueva y conflictiva realidad que se les plantea, esto es, la disyuntiva de sobrevivir o desaparecer para siempre. En Barranca abajo puede percibirse esta circunstancia nítidamente. El anciano gaucho Don Zoilo Carvajal, al igual que algunos miembros de su entorno afectivo, ha perdido la solidez de los rasgos atávicos (fortaleza, intrepidez, juventud) que siempre le caracterizó. La bravura y arrojo inherentes al gaucho se presenta en la dramaturgia de 
Sánchez como un espectro degradado que le impide resistirse a una nueva sociedad argentina industrializada que se va imponiendo mediante medidas legislativas que afectarán decisivamente a la desaparición de su mundo, modificando las estructuras socioeconómicas del campo argentino.

La anagnórisis de Don Zoilo recogerá una profunda reflexión de sus errores que le han llevado a las dramáticas circunstancias de la pérdida de su propiedad: "No, no me defendí bien, no supe cumplir con mi deber ¿Sabe lo que debía hacer? ¿Sabe lo que debí hacer? ¡Buscar a su padre, a los jueces, a los letraos, juntarlos a todos ustedes, ladrones, y coserle las tripas, pa escarmiento de bandoleros y saltiadores!" (160). La llegada de las reformas legislativas de la ciudad acabará con el derecho consuetudinario del campo argentino y con los dominios del gaucho. Pero Sánchez escenificará de un modo muy preciso cómo la dramática resignación del gaucho está condicionada precisamente por esa degeneración atávica de una raza, que en otros tiempos fue brava y orgullosa, y sin embargo ahora es incapaz de ofrecer resistencia: "No lo hice porque soy un hombre manso de sí..." (160).

Más evidente resulta el tema de la degeneración somática en el caso de la hija de Don Zoilo. Robustiana es tildada despectivamente por su misma tía de "gaucha tísica" (165) y parece sufrir una tara congénita que pone de relieve la degeneración genético-hereditaria. Con la muerte de la frágil Robustiana y el posterior suicidio de Don Zoilo, Sánchez finaliza su drama, anticipando la extinción de una raza, la de los criollos gauchos, en una pampa que empieza a desnaturalizarse con la mecanización del campo y la economía de mercado.

La muerte de Don Zoilo supone también el final del ancestral sistema familiar patriarcal. La degeneración de los antiguos valores familiares se presenta en el drama de Sánchez como un modelo degradado y disfuncional. El viejo gaucho ha perdido el respeto de los suyos, y no sólo debido a una mala gestión de su hacienda o una difícil coyuntura económica. Don Zoilo reconoce su error, no ha sabido transmitir esos valores tradicionales que en este momento tanto añora, sobre todo a su mujer Dolores: "No te enseñé tampoco a ser güena, honrada y hacendosa. ¡Y güena madre sobretodo!'(180). De este modo Sánchez trata de mostrar cómo incluso la maternidad, un rasgo atávico por antonomasia, se presenta degenerado y contribuye de manera importante a la disfuncionalidad de la familia de Don Zoilo. La indiferencia y el egoísmo de la madre, ajena en todo momento a las problemáticas del hogar y de los hijos, precipitan la destrucción del núcleo familiar. En definitiva, lo que parece escenificar Sánchez a lo largo de Barranca abajo no es más que un proceso 
degenerativo de carácter endémico de unos rasgos atávicos que termina por condenar al modelo patriarcal tradicional criollo a su desaparición.

Sin embargo, si el papel de la madre en Barranca abajo queda en entredicho a causa de una actitud maternal degenerada por su escaso apego al núcleo familiar, en La pobre gente, Mónica será un ejemplo de ese atavismo materno a la hora de proteger a sus hijos. En este drama de ambiente urbano, Mónica, madre de una familia extremadamente pobre, procurará proteger a su prole de los abusos de un padre alcohólico y violento, envilecido por el factor ambiental de la marginalidad: “¡Mira Felipe!... ¡Cuidadito con tocarme al chico! Si te has levantado con la luna, emprendela con todos, menos con estas pobres criaturas que demasiado hacen con sacrificarse por vos... Maltratame a mi si querés" (203). Por el contrario, el padre aparece como un modelo paradigmático de la degradación social típica del naturalismo de Zola, esto es, el hombre envilecido moralmente por el alcohol, sin trabajo, que ejerce continuamente la violencia doméstica y explota laboralmente a sus hijos menores de edad para que trabajen para él. ${ }^{3}$ Su perversidad alcanzará el clímax más dramático cuando el padre fuerza a su hija a tener relaciones sexuales no deseadas con su jefe para que ella pueda seguir costeándole su adicción al alcohol.

La escenificación de estas problemáticas sociales en la dramaturgia de Sánchez no sólo viene a advertir al público la degradación de las relaciones familiares tradicionales, acentuadas con los factores ambientales de la miseria y la precariedad económica. El naturalismo de Sánchez también lleva a escena una denuncia contra las políticas derivadas de un positivismo ideológico llevadas a cabo por un gobierno insensible, y cuyas dramáticas consecuencias son sufridas por los más necesitados.

Tanto la pampa argentina como la ciudad se hallan envueltas en un proceso de transición entre dos modos de concebir la productividad; por un lado la ganadería extensiva y la manufactura tradicional de la gran ciudad y por otro, la incipiente mecanización tanto en el ámbito rural como urbano. La imposición desde el poder de la mecanización del campo trae consigo reformas en la ley de propiedad como en el caso de Barranca abajo, y repoblación de emigrantes europeos, tal como puede observarse en el caso del emigrante emprendedor Nicola en La gringa, que provocará que el modo de vida del gaucho desaparezca para siempre. En la ciudad, la mecanización de las fábricas conllevará un abaratamiento de la mano de obra que derivará en un aumento del desempleo adulto y un incremento de la contratación de menores de edad, como puede observarse en La pobre gente. 
Durán-Cerda señala muy acertadamente hasta qué punto este conjunto de problemáticas es recogido en la obra del autor uruguayo:

El conflicto caducidad-modernidad alcanzó la sensibilidad de Florencio Sánchez, primero porque era un signo propio de los tiempos en la órbita de influencia en Buenos Aires [...] así se comprometió a representar aquellos cambios profundos en que la transición se operaba entre dos épocas más que entre dos siglos. (47)

La rapidez de estos cambios sociales generará una crisis en el ámbito de la familia tradicional criolla, pero no será el único factor determinante. Otro componente importante será la emigración europea, sobre todo la italiana, que incidirá de manera notable y que afectará principalmente a la transformación de la familia y de la economía. La emigración generará un nuevo modelo familiar alternativo al patriarcado tradicional criollo y su economía. La nueva familia pasa a convertirse en una unidad económica productiva, como puede observarse en La gringa, donde todos sus miembros trabajan en la explotación junto a los operarios.

Igualmente estos cambios socio-económicos tienen como factor determinante la inversión de los emigrantes, tal como sostiene Durán-Cerda (50), y que generará una súbita industrialización, creando así esta serie de desajustes económicos en la población criolla. Sin embargo, el mayor cambio se derivará de la dialéctica social entre la población europea entrante y la población criolla. Puede observarse en La gringa cómo esta dialéctica entre los locales y los recién llegados provoca un enfrentamiento generacional. En esta última pieza de Sánchez se presenta al gaucho Don Cantalicio, de mentalidad muy semejante a la de Don Zoilo en Barranca abajo, que pretende seguir manteniendo su antigua forma de vida a toda costa, frente a su hijo Próspero, que adopta una postura más abierta y flexible frente a los nuevos tiempos y a la mentalidad de los nuevos repobladores de la pampa.

Próspero va a mantener una actitud crítica hacia su padre, no ya sólo por su lamentable situación económica, sino por su mentalidad patriarcal y autoritaria, aferrada a un modo de producir que ya económicamente estaba caduco, como es la ganadería extensiva. Próspero reprochará a su padre hasta qué punto él es el propio culpable de su propia ruina: "Si usted me hubiese dado el campito cuando yo se lo pedí pa sembrarlo, no se vería en este trance; pero se empeñó en seguir pastoreando esas vaquitas criollas que no sirven ni pa... insultarlas" (115). Sánchez viene a contraponer en escena dos modelos de relaciones familiares, la de Don Cantalicio y la de Nicola, el primero es orgulloso, soberbio y autoritario con su hijo, y el segundo deposita su total 
confianza y el futuro de su industria en su hijo. Próspero se verá forzado a abandonar la explotación de su padre, mientras Nicola, por el contrario, mandará a su hijo a la ciudad de Buenos Aires para que estudie ingeniería y aplique en un futuro no muy lejano esas últimas innovaciones tecnológicas a la explotación familiar agraria.

El surgimiento de este nuevo modelo familiar como unidad económica productiva, que viene a estar representado por Nicola en La gringa, se contrapone con la que se representa en Barranca abajo, cuyos ingresos los proporciona Don Zoilo y en La pobre gente, los niños. De este modo, la inmigración parece dejar su impronta en el modelo productivo familiar, que integra a todos sus miembros. Así lo constata Próspero en La gringa, cuando habla de la virtud de las mujeres "gringas" que se contrapone con la mujer criolla:

Búsquenme la última gringuita de éstas y verán que mujer les sale... compañera pa todo...habituadas al trabajo, hechas al rigor de la vida, capaz de cualquier sacrificio por su hombre y sus hijos... ¡A Amalaya nos fuéramos juntando todos los hijos de criollo y de gringo, y verían qué cría! (112)

El final de La gringa no puede ser más revelador. Próspero, como representante de esa generación joven de criollos que ha de convivir con emigrantes europeos, parece adaptarse a los nuevos tiempos. Sabe que el porvenir de la tierra lo representa el desarrollo tecnológico y se convertirá en operario de máquinas agrícolas, desligándose definitivamente del antiguo modo de vida del gaucho. Don Cantalicio, representante genuino de esa casta orgullosa que pastoreaba por la pampa, aparecerá al final de la obra como un anciano obsoleto y mutilado, precisamente por una de esas máquinas agrarias a las que tanto se oponía.

De esto último, podría deducirse fácilmente que el pensamiento de Sánchez podría caer en la matriz ideológica del positivismo y la industrialización capitalista, sobre todo por el final feliz de la trama. Sin embargo, la presencia del ombú en La gringa viene a incidir en la necesidad de la lucha por preservar la tradición frente a los nuevos tiempos. Para el italiano Nicola, el ombú tan sólo es "un árbol criollo que no sirve ni pa leña... y que no sirve más que pa que le hagan versitos de Juan Moreira" (135). Sin embargo, su hija Victoria, enamorada de Próspero, defenderá impetuosamente que no sea arrancado, que quede como algo del pasado de esa naturaleza que está siendo transformada por las máquinas. De este modo podría afirmarse que el pensamiento de Sánchez incide más en la denuncia de estos cambios traumáticos, 
esto es, que se arranque de raíz todo el sistema socio-económico tradicional, y donde propone una conciliación entre el progreso de los nuevos tiempos con el menor daño posible a la tradición.

Es precisamente lo que hace Sánchez en La gringa, proponer un modelo de integración pacífica de lo nuevo frente a lo tradicional, metaforizado con la boda del criollo Próspero con la gringa Victoria y la permanencia del ombú en la explotación de Nicola como metáfora de la tradición gauchesca. Por otro lado, Sánchez no es ajeno al ambiente cientificista de la época ni tampoco a la visión positivista en conexión con la genética y la identidad nacional a la hora de escenificar el tema de la degeneración/regeneración. En Barranca abajo y La pobre gente se incide más en la degeneración atávica de una sociedad-en plena ebullición de transformaciones sociales, sin embargo en La gringa puede advertirse una reescritura o revisión crítica de las narrativas fundacionales decimonónicas.

El concepto de ficción fundacional, según Doris Sommer, se basa en ciertas narrativas del siglo XIX que se proyectaron como un mecanismo literario para dotar de contenidos a una ideología sobre la cohesión nacional de un estado postcolonial. Según Sommer, la unión sexual inauguraba un proyecto de familia de carácter adánico que servía de modelo para la fundación de la nación y su identidad. La representación del gaucho criollo o el colectivo urbano y su modelo familiar patriarcal aparece en la dramaturgia de Sánchez como modelos en crisis, caducos o necesitados de una reelaboración. De este modo puede advertirse en La gringa una línea "re-fundacional," esto es, una narrativa alternativa que re-defina un modelo de identidad nacional agotado. Desde esta perspectiva, no es nada extraño que esa nueva unión sexual del criollo Próspero y Victoria vaya encaminada no sólo a la supervivencia de la raza criolla, sino también a su fortalecimiento, en definitiva, dotar de una nueva raza a la nación a través del cruce genético: “¡Mire qué linda pareja! ...Hija de gringos puros...Hijo de criollos puros... De ahí va a salir la raza fuerte del porvenir" (114).

Esta aproximación de corte darwinista, donde la adaptación al medio y la selección natural de las especies son los factores determinantes para la supervivencia, parece estar presente no sólo en la dramaturgia de Sánchez, sino también en el pensamiento sarmientista. La obra Conflicto y armonías de las razas de América (1883) de Domingo Faustino Sarmiento llegaba a la conclusión de que el destino histórico de la nación argentina y su desarrollo pasaba por una europeización de la raza, poniendo como ejemplo paradigmático a Estados Unidos y su política segregacionista. Esta línea de pensamiento 
tuvo su continuación con las tesis de José Ingenieros, que sienta las primeras bases de las políticas de blanqueamiento a través de la emigración europea en su ensayo La formación de una raza argentina, recogido años más tarde en su compendio Sociología argentina (1913). Sin embargo, el gobierno argentino ya había empezado a desarrollar políticas de inmigración en las postrimerías del siglo XIX, principalmente italianos y españoles, así como polacos y judíos en menor medida.

Sánchez parece ver el tema de la inmigración trasatlántica como un elemento positivo y favorecedor para ese proyecto utópico de nación en $L a$ gringa, como una posible solución a las crisis de las estructuras económicas, sociales y familiares, sin que por ello deje a un lado la denuncia de las injusticias sociales contra los más desfavorecidos como puede observarse en Barranca Abajo y La pobre gente. El naturalismo de denuncia social de estas dos últimas piezas parece ser el instrumento para constatar esas narrativas fundacionales de las que habla Sommer. Coincido con Nouzeilles cuando afirma que,

en contradicción con la armonía amorosa de los romances fundacionales, los amantes se pelean y terminan por despreciarse: ni sus cuerpos ni sus temperamentos resultan compatibles. Leído en clave darwinista, el circuito causal de sus historias eróticas confirma el status quo y la segregación de los grupos sociales dispares. (15)

La degeneración de las relaciones familiares, condicionadas en gran medida por la crisis de las estructuras económicas y sociales, parece apuntar a la figura paterna, tal como puede observarse en La pobre gente o Barranca Abajo. Se trata de un cuadro clínico de un cuerpo social enfermo, sin defensas para hacer frente a una serie de problemáticas que las nuevas condiciones económicas requieren para la supervivencia. Sánchez denuncia cómo la nueva sociedad argentina amputa esos miembros de ese cuerpo social que no son útiles para los nuevos modos de productividad. Así puede verse en la imagen final del gaucho Don Cantalicio, un anciano inutilizado, cuyo brazo fue amputado por una máquina cosechadora en La gringa.

En definitiva, y como se ha podido observar a lo largo de este estudio, Sánchez parece seguir muy de cerca los postulados de Zola del naturalismo, no sólo para mostrar las problemáticas e injusticias que imperan en una sociedad en plena transición económica hacia el capitalismo y darle respuesta. $\mathrm{Su}$ dramaturgia entronca los problemas sociales mediante el naturalismo de Zola, pero Sánchez trata de adaptarlo a las circunstancias específicas de la sociedad argentina, intentando reescribir una nueva narrativa ideológica 
fundacional para la formación de una identidad nacional, donde parece advertirse la línea sarmientista y la de José Ingenieros. Se trataría de buscar a través de su naturalismo en el teatro una regeneración de la sociedad, que integraría la tradición criolla con la nueva visión que aportan las nuevas corrientes migratorias europeas.

\section{University of Louisiana at Lafayette}

\section{Notas}

1 Las reformas legislativas ya empezaron en la época de Sarmiento. Gastón Gori menciona cómo Oroño, gobernador de Santa, ya legisló en 1866 medidas para el reparto de la tierra para su cultivo, sin embargo las familias criollas se resistieron a abandonar la ganadería. Bajo el pensamiento de "el lazo embrutece y el arado civiliza," los gobiernos que llegaron posteriormente fueron repartiendo tierras a los extranjeros que estuvieran dispuestos a cultivar la tierra (17). Gori señala que "el crecimiento demográfico y económico operado en gran escala, y en ascenso la libre penetración de los extranjeros en nuestro territorio impuso una revisión y reforma de nuestro derecho público y privado como problema pendiente" (90). Sin embargo, Gori advierte que desde los mismos gobiernos surgió una oligarquía latifundista que mediante artificios legales fue acaparando la propiedad de las tierras. Finalmente la mecanización del campo en las explotaciones latifundistas agrarias terminaron por imponerse a finales del siglo XIX. El gaucho en apenas cincuenta años quedó relegado a una presencia testimonial, pese a convertirse en un ícono cultural de la nación argentina (95).

2 El impacto de la inmigración en las urbes igualmente creará conflictos sociales y brotes xenofóbicos. Tal como sostiene Carl Solberg: "The crowds of tired, dirty, and unemployed drifters and beggars who gathered in the majors cities of both nations constituted an eminently visible problem." An example of such xenophobic slanders in the play La pobre gente by Florencio Sánchez. An argentine woman asks a friend, "Do you remember the turca who used to live upstairs? ... Well, now she is rich and is earning all she wants by...sending her children out to beg" (95).

3 Tal como apunta Gabrielle Nouzeilles, la significación del alcohol en la degradación moral de los personajes de las novelas del naturalismo europeo, tales como La Taberna de Emile Zola, influirán en diversos protagonistas del naturalismo argentino.

\section{Obras citadas}

Durán-Cerda, Julio. “Otra valoración de Florencio Sánchez.” Confluencia 1.1 (1985): 43-52.

Gori, Gastón. La pampa sin gaucho. Influencia del inmigrante en la transformación de los usos y costumbres en el campo argentino en el siglo XIX. Buenos Aires: Editorial Raigal, 1952.

Ingenieros, José. Sociología argentina. Buenos Aires: Editorial Losada, 1946. 
Morel, Benedict. Traité des dégénérescences physiques, intellectuelles et morales de l'espèce humaine. París: J. B Bailliére, 1857.

Nouzeilles, Gabriela. Ficciones somáticas: Naturalismo, nacionalismo y políticas médicas del cuerpo. Rosario: Beatriz Viterbo Editora, 2000.

Rossel, Avenir. El lenguaje de Florencio Sanchez. Montevideo: Comisión Nacional de Homenaje del Sequiscentenario de los Hechos Históricos de 1825, 1975.

Sánchez, Florencio. Teatro completo de Florencio Sánchez. Sus veinte piezas, seguidas de sus prosas, ordenadas, prologadas y anotadas por Dardo Cuneo. Buenos Aires: Editorial Claridad, 1964.

Sarmiento, Domingo Faustino. Conflicto y armonías en las razas de América. Editorial Luz de Día, 1956.

Solberg, Carl. Inmigration and Nationalism. Argentina and Chile, 1890-1914. Austin: U of Texas P, 1970.

Sommer, Doris. Ficciones fundacionales. Las novelas nacionales de América Latina. Buenos Aires: Fondo de Cultura Económica, 2004.

Zola, Emile. El naturalismo. Edición y estudio introductorio de Laureano Bonet. Barcelona: Península, 1985. 